\title{
Clinical presentation of vernal keratoconjunctivitis in College of Medical Sciences, Bharatpur
}

\author{
Polina Dahal $^{1}$, Sanjeet Bhattarai ${ }^{2}$ \\ ${ }^{1}$ Lecturer, Dept of Ophthalmology, ${ }^{2}$ Intern, College of Medical Sciences, Bharatpur, Nepal.
}

\author{
Correspondence \\ Dr. Polina Dahal, \\ Dept of Ophthalmology, \\ College of Medical Sciences-TH, \\ Bharatpur, Nepal \\ Email: \\ polinadahal@yahoo.com
}

DOI: http://dx.doi.org/10.3126/ jemsn.v11i2.13670

\begin{abstract}
Background \& Objectives: To evaluate the different clinical presentation of Vernal Keratoconjunctivitis (VKC) in our context. Materials \& Methods: Ninety diagnosed VKC patients attending the outpatient department of College of Medical Sciences from 1st March 2014 to 1 st June 2015 were enrolled in the study. Results: The study revealed male predominance $(83.33 \%)$. Commonly occurring symptoms were itching $(100 \%)$ and redness $(80 \%)$. Commonest sign was tarsal papillae $(100 \%)$. Conjunctival hyperemia was seen in $94.1 \%$ cases and 180 eyes of 90 cases showed Vernal Keratoconjunctivitis. Conclusion: The clinical presentation of VKC patients in our context are very much similar to the findings of the other study done in Nepal and other parts of the world. Commonly occurring symptoms are itching, redness and commonly occurring signs are tarsal papillae and conjunctival hyperemia. Key words: 'Cobble-stone' appearance, eyelid erythema, vernal keratoconjunctivitis
\end{abstract}

Citation: Dahal P, Bhattarai S. Clinical presentation of vernal keratoconjunctivitis in College of Medical Sciences, Bharatpur . JCMS Nepal. 2015;11(2):17-19.

\section{INTRODUCTION}

Vernal Keratoconjunctivitis is seasonally recurring, bilateral inflammation of the conjunctiva, occurs in male children with invariable personal or family history of atopy. ${ }^{1}$ VKC is characterized by interstitial inflammation of the cornea with periodic incidence of self- limited character. ${ }^{2}$ Mild cases of VKC tend to remit with nonspecific and supportive therapy. In contrast, severe cases are usually more protracted with remission/relapse occurring for a prolonged period. In severe tarsal VKC, giant papilla are classically observed on the upper tarsal plate, giving the classic 'cobble-stone' appearance. Corneal ulcer can occur from the effect of eosinophilic granular proteins on corneal epithelium and by physical trauma by intense eye rubbing. Topical corticosteroids, often required for controlling symptoms and signs in severe $\mathrm{VKC}$, can lead to serious ocular complications. ${ }^{3}$ Topical Immunomodulators like Cyclosporine $\mathrm{A}$ and Tacrolimus are investigated in treatment of $\mathrm{VKC}$ but severe VKC responds promptly to those topical preparations mostly within a month. ${ }^{4}$

VKC is a disease of warm climate. ${ }^{5,6}$ It is more common in the tropics than in northern climates. However, it is not unusual to see occasional vernal conjunctivitis patients throughout the United States and Canada. The prevalence of VKC in Europe ranges from 1.2 to 10.6 cases per 10,000 population, although the prevalence of associated corneal complications is much lower (0.3-2.3 per 10,000 population). $^{7}$ Young people are typically affected. ${ }^{8}$ In VKC, a nonspecific hyperreactivity occurs that explain the ocular symptoms induced by nonspecific stimuli - such as wind, dust and sunlight - as well as their variability, which is not related to allergen levels in the environment. Indeed, skin tests and/or serum Ig E antibody tests to common allergens are often negative. ${ }^{5}$ The immunopathogenesis appears to involve both Type I and Type IV hypersensitivity reactions. Type I immediate hypersensitivity reactions typically occur within minutes after application of an allergen. When involving the eyelids, these reactions are associated with itching, eyelid erythema and swelling, and conjunctival redness and chemosis. Delayed Type IV hypersensitivity reactions to medications may begin 24 to 72 hours following instillation of a topical drug. However, Ig E-dependent hypersensitivity has been observed as the important factor for the pathogenesis. Ig E sensitizes cells like mast cells and basophils, resulting in degranulation with a release of vasoactive amines. These amines are responsible for clinical manifestations of VKC. The conjunctival inflammatory infiltrate in VKC consists of eosinophils, lymphocytes, plasma cells, and monocytes. ${ }^{1}$

The purpose of the study is to find the different clinical presentation of the disease in the patient 
attending the outpatient of CMS TH. As the disease is an unusually severe sight-threatening allergic eye disease, occurring mainly in children. Conventional therapy for allergic conjunctivitis is generally not adequate for VKC. Pediatricians and allergists are often not familiar with the severe clinical symptoms and signs of VKC. As untreated VKC can lead to permanent visual loss pediatrician should be aware of allergen and the management and therapeutic options for this disease to allow patients to enter clinical remission with the least side effects and sequelae. $^{6}$

\section{MATERIALS AND METHODS}

All the cases $(n=90)$ of VKC, diagnosed on the basis of history and clinical findings attending the College of Medical Sciences outpatient department from 1st March 2014 to 1st June 2015 were enrolled in the study. Study period was of 14 months duration. Informed verbal consent was taken from all the cases in adult patients and from parents in cases of children before taking the cases for the study. Detailed history of all the cases was taken. All selected cases were examined in detail general examination and ocular examination was done to rule out other allergic diseases and also to rule out others types of allergic conjunctivitis and other external ocular conditions besides VKC. In ocular examination starting from visual acuity, slit lamp examination of lid, conjunctiva (details of conjuctival parts palpebral, bulbar and fornic), cornea, anterior chamber, iris, pupil, lens and examination of posterior segment was also done.

Inclusion criteria of VKC included in the study were: both eye involvement, itching, scanty tenacious discharge (yellowish-white), tarsal papillae, limbal elevation and trantas' spot.

\section{RESULT}

The total number of cases included in the study were 90 and the total number of eyes were 180 . Age of patients ranged from two to 27 years old. Maximum number of patients were in age group six two 12 years. Five cases were four years old girl and five were two years old child. Seventy five $(83.33 \%)$ cases were male and $15(16.66 \%)$ were female. Sixty five $(72.22 \%)$ cases were students, $10(11.11 \%)$ cases were service holders, five $(5.55 \%)$ were policeman.

Table 1: Symptoms of VKC cases.

\begin{tabular}{lll} 
Symptoms & Number & Percent \\
Itching & 90 & 100 \\
Redness & 72 & 80 \\
Discharge & 72 & 80 \\
\hline
\end{tabular}

Table 2: Signs of VKC cases

$\begin{array}{lll}\text { Signs } & \text { Number } & \text { Percent } \\ \text { Tarsal Papilla } & 90 & 100 \\ \text { Conjunctival Hyperemia } & 85 & 94.1 \\ \text { Tarsal Papillae } & 90 & 100 \\ \text { Conjunctival pigmentation } & 14 & 14.7 \\ \text { Shield Ulcer } & 1 & 1.5 \\ \text { Pannus } & 13 & 14.7 \\ \text { Mechanical Ptosis } & 2 & 2.9 \\ \text { SPK } & 1 & 1.11 \\ \text { Filamentary keratitis } & 1 & 1.11 \\ \text { Steroid Induced cataract } & 1 & 1.11 \\ \text { Upper tarsal conjunctival scarring } & 1 & 1.11\end{array}$

Presentation of the clinical features occurred in different episodes like first, second, third and more than three episodes and persistent group when it was present throughout even with the treatment for duration of three months or more. In maximum number (37 or $41.2 \%$ ) of cases it had occurred in more than three episodes. Second most common group was of persistent with $23(26.5 \%)$ cases.

Majority of the cases were of mixed clinical type of VKC (72 cases, $80.3 \%$ ) followed by palpebral VKC (16 cases, 17.6\%) and limbal VKC (two, cases $2 \%$ ). Among the mixed type, it had involved unilateral eye in 12 cases $(16.66 \%)$ and bilateral in 60 cases $(83.33 \%)$.

Table 3: Sex distribution in VKC

$\begin{array}{lll}\text { Sex } & \text { Number } & \text { Percent } \\ \text { Male } & 75 & 83.33 \\ \text { Female } & 15 & 16.67\end{array}$

\section{DISCUSSION}

In all forms of allergic eye diseases, the clinical response is caused by mast-cell activation due to either an antigen-mast cell linkage or T-cell activation of mast cells. The activation of conjunctival mast cells leads to the release of histamine, prostaglandin D2, leukotriene C4, tryptase, chymase, platelet activating factor, and other chemo-attractants. This further attracts eosinophils and neutrophils. ${ }^{9-12}$

$\mathrm{VKC}$ and $\mathrm{AKC}$ are traditionally seen as type I immunoglobulin (Ig) E- mediated hypersensitivity reactions. However, current evidence shows that eosinophils and their major basic proteins are also important in the chronic allergic process of ocular surface inflammation and epithelial damage. ${ }^{13}$

Vernal keratoconjunctivitis is a chronic seasonally exacerbated bilateral allergic ocular inflammation, affecting children and young adults with male 
predominance. In this study the peak age of onset of disease is (six to 12 years); male preponderance 75 (83.33\%) with M:F (3:1); seasonal exacerbation pattern are very much similar to other parts of the world reports with peak incidence at six to 10 years of age; male to female ratio 3.2:1 and seasonal exacerbation in between April and August. ${ }^{14}$

It has been established by several studies carried out in different parts of the world that itching is the commonest symptom followed by tenacious discharge. The commonest sign found is tarsal papillae followed by conjunctival injection. In a study done by Ballas et al, ${ }^{10}$ out of 122 patients (244 eyes) 100\% had marked itching, 91\% had swollen lids, $86 \%$ had discharge and tearing, $85 \%$ had burning and stinging; in 77\%, foreign body sensation was present 6 . Similarly, in the same study, 63\% had conjunctival injection, $49 \%$ had conjunctival chemosis, $16 \%$ had lid oedema, $9 \%$ had conjunctival mucus and $1 \%$ had keratitis.

The results are very similar to our study. The commonest symptom among VKC cases in our study was itching $(100 \%)$ followed by redness of eyes and discharge (80\% each) and the commonest sign was tarsal papillae $(100 \%)$ followed by conjunctival hyperemia (94.1\%) in 180 eyes of 90 cases of VKC. Majority of the cases in our study were in mixed clinical type of VKC (72 cases, $80.3 \%$ ) while 16 cases $(17.6 \%)$ were palpebral VKC and limbal in two cases. Twelve cases were unilateral $(16.66 \%)$ and 60 cases $(83.33 \%)$ were bilateral.

The clinical type reported by other study from Mediterranean country Egypt was 17.4\% palpebral, $11.2 \%$ bulbar ( limbal) and $71.4 \%$ mixed. Studies have shown that in Mediterranean countries bulbar type is common. In United States, palpebral type is common $(60 \%)$ than bulbar $(55 \%){ }^{11}$

\section{CONCLUSION}

Vernal keratoconjunctivitis (VKC) is an unusually severe sight-threatening allergic eye disease, occurring mainly in children. Conventional therapy for allergic conjunctivitis is generally not adequate for VKC. Pediatricians and allergists are often not familiar with the severe clinical symptoms and signs of VKC. As untreated VKC can lead to permanent visual loss, so the clinical presentation, its pathogenesis and treatment modalities are very important to prevent the blindness. It encompasses different clinical entities based on the assumption that the classical Type I and type IV hypersensitivity mechanism is responsible for all clinical forms of the disease. The clinical presentation of VKC patients in our context are very much similar to the findings of the other study done in Nepal and other parts of the world.

\section{REFERENCES}

1. Carol L. Dondrea, Cristrine Arturo. Basic and clinical concepts of corneal and external eye disease. Americal Academy of Ophthalmology, 94120-7424 San Francisco: Lifelong Education for Ophthalmology; 2000.p.195-200.

2. Pokharel S. Vernal keratoconjunctivitis: modes of presentation in Nepalese population. Kathmandu University Medical Journal. 2007;5(4):526-30.

3. Vichyanond P, Pacharn P, Pleyer U, Leonardi A. Vernal keratoconjunctivitis: a severe allergic eye disease with remodeling changes. Pediatr Allergy Immunol. 2014 Jun;25(4):314-22. DOI: 10.1111/pai.12197. Epub 2014 Jan 20.

4. Vichyanond P, Kosrirukvongs P. Use of cyclosporine A and tacrolimus in treatment of vernal keratoconjunctivitis Curr Allergy Asthma Rep. 2013 Jun;13(3):308-14. DOI: 10.1007/s11882-013-0345-0.

5. Jun J, Bielory L, Raizman MB. Vernal conjunctivitis. Immunol All Clin North Am. 2008;28:5982. DOI: $10.1016 /$ j.iac.2007.12.007.

6. Kumar S. Vernal keratoconjunctivitis: a major review. Acta Ophthalmol. 2009;87:133-147. DOI: 10.1111/j.1755-3768.2008.01347.x.

7. Bremond-Gignac D, Donadieu J, Leonardi A, Pouliquen P, Doan S, Chiambarretta F, et al. Prevalence of vernal keratoconjunctivitis: a rare disease. $\mathrm{Br} J$ Ophthalmol. 2008;92(8):1097-102. DOI: 10.1136/ bjo.2007.117812.

8. Ostler HB. Vernal conjunctivitis. In: Ostler HB, editor. Diseases of the external eye and adnexae: a text and atlas. 1st ed. Baltimore: Williams \& Wilkins; 1993. p. 125 .

9. McGill JI, Holgate ST, Church MK, Anderson DF, Bacon A. Allergic eye disease mechanisms. $\mathrm{Br} \mathrm{J}$ Ophthalmol. 1998;82:1203-14.

10. McGill J. Conjunctival cytokines in ocular allergy. Clin Exp Allergy. 2000;30:1355-7.

11. Church MK, McGIll JI. Human ocular mast cells. Curr Opin Allergy Clin Immunol. 2002;2:419-22.

12. Proud D, Sweet J, Stein P, Settipane RA, Kagey-Sobotka A, Friedlaneder $\mathrm{MH}$, et al. Inflammatory mediators release on conjunctival provocation of allergic subjects with allergen. J Allergy Clin Immunol. 1990;85:896-905.

13. Trocme SD, Kephart GM, Bourne WM, Buckley RJ, Gleich GJ. Eosinophil granule major basic protein deposition in corneal ulcers associated with vernalkeratoconjunctivitis. Am J Ophthalmol. 1993;115:640-3.

14. McGill JI, Bacon A: Allergic eye disease mechanism. BJO. Oct 1998; 82: 1203-14. 